\title{
¿DEL EJIDO AL PERIURBANO? Dos casos de reconfiguración de periferias en ciudades intermedias uruguayas
}

\author{
Arq. Leonardo Altmann Macchio \\ Instituto de Teoría de la Arquitectura y Urbanismo- ITU- FADU- UDELAR Uruguay. \\ Maestría en Estudios Urbanos- Universidad Nacional de General Sarmiento. Argentina. \\ leonardoaltmann@gmail.com
}

\section{RESUMEN:}

En Uruguay, país tempranamente urbano y macrocefálico, de lento crecimiento demográfico en el largo plazo, las ciudades intermedias incrementaron, en las últimas décadas, su protagonismo en la estructura territorial nacional. Aunque el concepto de periurbano suele asociarse a las heterogeneidad de usos del suelo de la interfase urbano- rural de las áreas metropolitanas (Carter, Barsky, Hernandez Puig), en las periferias de muchas ciudades medias de Uruguay, se están dando una inédita convivencia -desarticulada y conflictiva- de usos de tipo logístico, agroindustriales, residenciales, productivos; así como procesos socio- territoriales con diferencias notorias a la configuración de la interfase urbano- rural del período de sustitución de importaciones (1930-1973) y la primera apertura neoliberal (1973-1990). Se pretende analizar esta reconfiguración de las periferias, desde el concepto de periurbano, al evidenciarse una reconversión de usos, deficiente cobertura infraestructural, expansión urbana sin correlato poblacional, y un rezagado marco planificador estatal y local.

Palabras clave: Periurbano, Ciudades intermedias, Ordenamiento Territorial.

\begin{abstract}
:
In Uruguay, an early urban and macro-cephalic country, with a slow demographic growth in the long term, intermediate cities have increased their prominence in the national territorial structure in recent decades. Although the concept of peri-urban is often associated with the heterogeneity of land uses of the urban-rural interface of the metropolitan areas (Carter, Barsky, Hernandez Puig), in the peripheries of many medium-sized cities of Uruguay, an unprecedented coexistence is taking place - disjointed and conflictive- of logistic, agroindustrial, residential, productive uses; as well as socio-territorial processes with notable differences in the configuration of the urban-rural interface of the period of import substitution (1930-1973) and the first neoliberal opening (1973-1990). The aim is to analyze this reconfiguration of the peripheries, from the periurban concept, as evidenced by a reconversion of uses, deficient intrastructural coverage, urban expansion without population correlation, a lagging state and local planning framework.
\end{abstract}

Keywords: Peri-urban, Intermediate Cities, Territorial Organization. 


\section{ENCUADRE Y OBJETIVOS}

Dentro de las primeras etapas de elaboración de tesis de Maestría, este trabajo aporta a la identificación y análisis de la transformación de los bordes urbano- rural en las Ciudades Intermedias de Uruguay (CIU) en las últimas décadas.

Las CIU protagonizaron procesos de crecimiento poblacional y expansión urbana generalmente deficientes en infraestructura y servicios urbanos, con el impacto socio-ambiental que conlleva, mientras los sectores consolidados de la trama urbana perdían población (Martínez, Altmann, Rodríguez; 2013). En éstas expansiones urbanas no sostenibles, han convivido tejidos residenciales tradicionales o conjuntos habitacionales de programas públicos de vivienda, con usos no habitacionales (enclaves logísticos, zonas francas, agroindustrias, espacios en producción) o habitacionales de tipo enclave en baja densidad para altos ingresos.

La reconfiguración de los bordes urbano- rural no es un fenómeno exclusivo del Uruguay, en tanto está asociada a los territorios del capitalismo contemporáneo. Pero en Uruguay, estas transformaciones en las ciudades intermedias han estado en parte invisibilizadas como parte del tardío descubrimiento de las CIU como objeto de estudio, particularmente en sus dimensiones socio- territoriales y ambientales.

Paralelamente, Uruguay aprobó una legislación nacional sobre ordenamiento territorial (ley de Ordenamiento Territorial y Desarrollo sostenible, 2008). Los planes urbano- territoriales de diversa escala (locales, departamentales, regionales), que de ella derivan, operan principalmente en el ámbito de la categorización de suelos por uso y en la definición de los procesos de transformación del mismo, dentro de un modelo territorial que se debe explicitar. ¿La planificación está validando y retroalimentando esta reconfiguración de periferias?

Para indagar en estas dinámicas se hará foco en dos fenómenos: la genealogía de las periferias de las ciudades intermedias del Uruguay, con énfasis en la caracterización por ciclos territoriales del Uruguay (Martínez y Altmann, 2016) y un análisis de la situación actual, donde el concepto de periurbano aparece como posible categoría que de cuenta del estado reconfiguración de la interfase urbano-rural en las ciudades intermedias.

A éstos efectos, se tomarán dos casos de estudio en centros urbanos diferentes condicionantes de ubicación, dinámicas demográficas, procesos fundacionales y roles en el sistema urbano nacional, y que, en buena medida expresan dos tipos de ciudades del Uruguay: Salto y Florida. La primera, históricamente fue la segunda ciudad del país luego de la capital y está situada al norte del río negro, donde hay menos ciudades, más pobladas, más alejadas entre sí y el sistema urbano muestra notorios saltos de jerarquía. La segunda es una localidad de menor peso demográfico, cercana a la capital y situada al sur del río negro, donde los centros urbanos son de menor tamaño, y con una distribución territorial más equilibrada. Ambas fueron fundadas en el período colonial.

\section{CIUDADES INTERMEDIAS EN EL MODELO TERRITORIAL URUGUAYO}

Durante el siglo $X X$, Uruguay consolidó tendencias que lo hicieron crecer poco y lento. El país fue tempranamente urbano y de precoces transiciones demográficas, teniendo un sello distintivo en el notorio macrocefalismo en torno a la capital, con niveles de primacía ${ }^{1}$ contundentes, aunque en leve descenso reciente:

"A inicios del siglo XX, Montevideo tenía casi 300.000 habitantes, el 30 \% de la población del país, pero representaba el 60 \% del país urbano, era la única ciudad de más de 20.000 habitantes y multiplicaba por quince a la segunda ciudad (Salto, 19.000 habitantes). Promediando el siglo XX, la capital llegó a tener el $46 \%$ de la población total del país, con 1.200.000 habitantes y multiplicar por veinte a la segunda ciudad (Salto, 58.000 habitantes). Sin embargo, actualmente, la ciudad de Montevideo ha estancado su crecimiento en poco más de 1.300.000 habitantes, multiplicando por doce a la segunda ciudad (Salto, 105.000 habitantes) y considerando los espacios metropolitanos, el Área Metropolitana de Montevideo, con casi 1.800.000 habitantes es trece veces mayor que la Aglomeración Maldonado- Punta del Este- San Carlos (135.000 habitantes)" (Altmann, 2017; 6).

1 Primacía urbana definida como el cociente entre la población del principal y segundo aglomerado urbano del país. 
Respecto a las Ciudades intermedias de Uruguay, su definición y su rol desde una lectura sistémica de los episodios urbanos del Uruguay, es relevante considerar la ausencia de una escala "intermedia" en la configuración o gestión del territorio uruguayo (Musso, 2005; DINOT, 1997).

Diversos trabajos coinciden, analizando génesis y evolución de los centros urbanos del país, (Martínez y Altmann, 2016, Martínez, Altmann, Rodríguez; 2013; Urruzola; 2011, Musso; 2004, Klaczco y Rial, 1981) que en el Uruguay urbano, se perfilan tres grandes categorías de localidades identificadas por "cualidades que refieren en primera instancia a sus tamaños respectivos (área y población) (y) Más allá del rol de la localización en el territorio, de cada localidad, sus dimensiones permiten reconocer identidades, problemáticas y desafíos claramente asociados a éstas categorías" (Urruzola, 2011; 112).: Área Metropolitana de Montevideo, Ciudades Intermedias y Pequeñas Localidades (PLU). La identificación de cada localidad con cada uno de éstos grupos es excluyente, por lo cual cada localidad del país pertenece a uno solo de ellos. En ese marco, y tomando las elaboraciones de la UIA (1996), el programa CIMES - UNESCO (Bellet y Llop, 2003), los aportes de Vapñarsky y Gorojovsky (1989) y los desarrollos en torno a las ciudades del Uruguay de Musso (2004) el Grupo de Investigación CSIC 1703 con sede en el Instituto de Teoría de la Arquitectura y Urbanismo de la FADU UDELAR ha definido a las Ciudades Intermedias del Uruguay como aquellos aglomerados urbanos con población mayor a 5000 habitantes y que no integran el conurbano de Montevideo metropolitano.

El comportamiento de éstos grupos de localidades en el reciente ciclo territorial del país muestra una creciente incidencia de las ciudades intermedias en el país urbano, en tanto el Área Metropolitana de Montevideo se retrae y las Pequeñas Localidades se muestran estables.

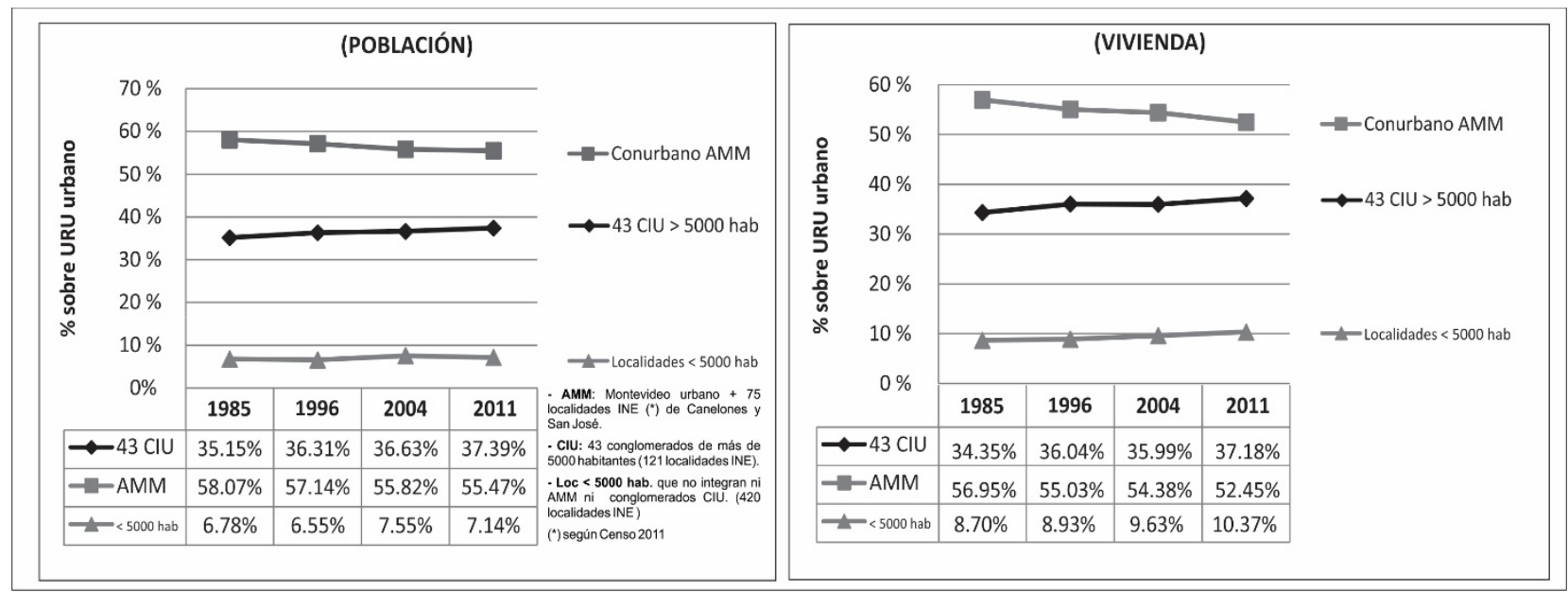

Imágen 01: Evolución demográfica del peso relativo de los grandes grupos de localidades del Uruguay Urbano (1985-2011) Fuente: Martínez, Altmann, Rodríguez (2013). 

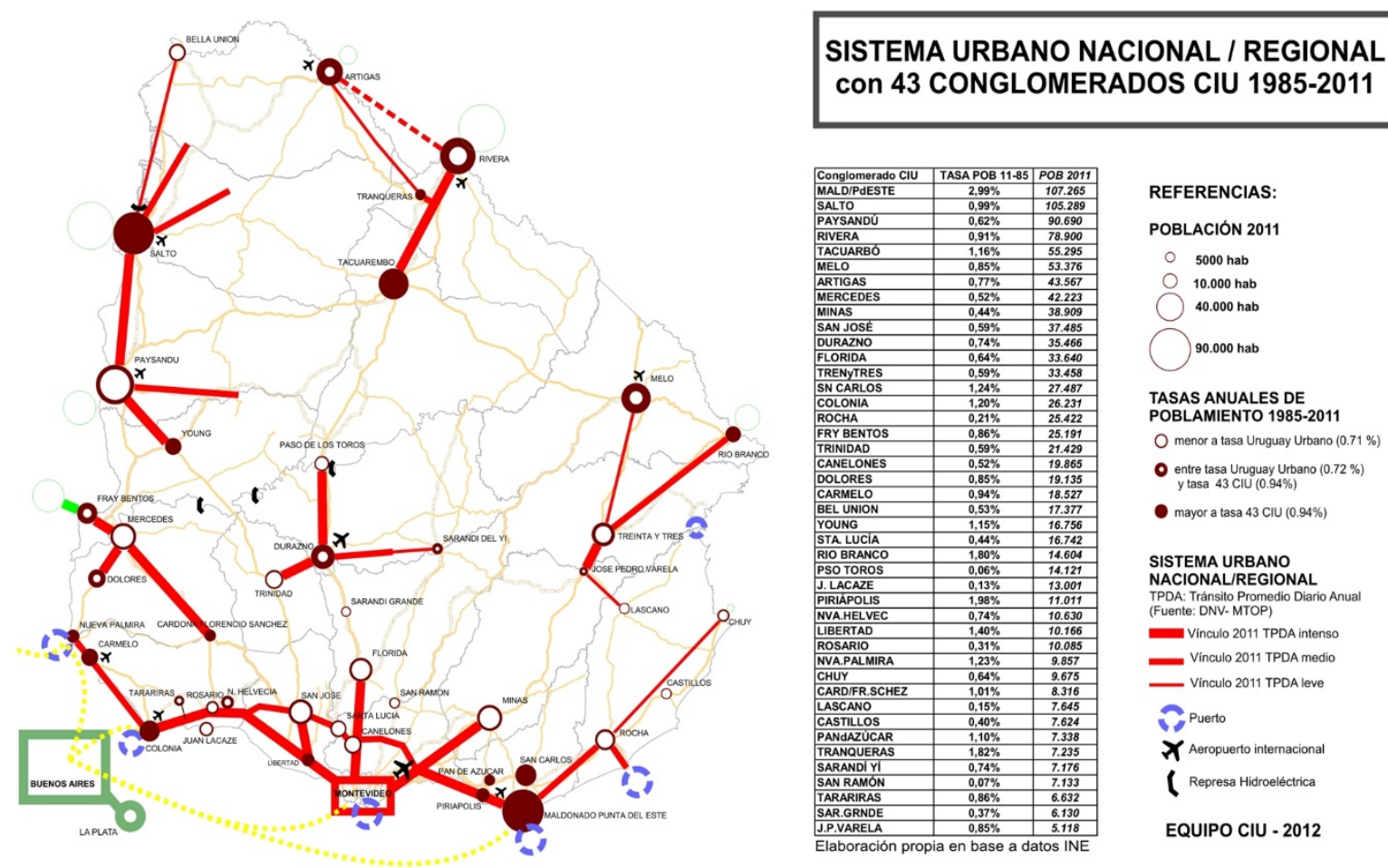

Imagen 02: Sistema urbano nacional. Ciudades intermedias según dinámica demográfica 1985-2011 y flujo de transporte promedio diario anual (TPDA) de pasajeros.

Fuente: Martínez, Altmann, Rodríguez (2013).

\section{HACIA UNA GENEALOGÍA DE LAS PERIFERIAS DESDE CICLOS TERRITORIALES}

En los procesos históricos del territorio uruguayo se aprecian variaciones y continuidades de las trayectorias de la economía, el estado y la sociedad. La economía puede ser vista desde los patrones de acumulación del capital (Pradilla Cobos, 2014), el Estado, desde la institucionalidad político- administrativa estatal y el marco normativo; y las transformaciones en la sociedad en la dinámica demográfica, condiciones de vida de la población o estructura de clases sociales. Los lapsos donde estos tres procesos guardan coherencia desde una lectura sistémica, perfilan etapas que denominamos ciclos territoriales.

Desde la academia o la gestión de políticas territoriales se ha esbozado la noción de ciclos históricos del territorio uruguayo (DINOT, 1997; Capandeguy, 2002), la caracterización de éstas etapas desarrolladas por Martínez y Altmann (2016) permite abrir un campo de análisis en que ciclo es utilizado como dispositivo analítico "capaz de identificar características y claves de los procesos urbano- territoriales del país, así como las variantes de modos de producción del territorio en los diferentes agregados urbanos (Área Metropoliana, Ciudades intermedias, Pequeñas Localidades) y en los espacios rurales" (Altmann, 2017; 7).

Ésto implica entender las claves de la configuración de las periferias de las ciudades intermedias en los diferentes ciclos (y sus fases) identificados en el Uruguay moderno:

- Sistema urbano tributario de la macrocefalia (1908-1973). Fases: Consolidación institucional y creación de entes autónomos y del Estado de bienestar en la inserción capitalista (1908-1929) e Implantación, auge y crisis del modelo de sustitución de importaciones y fomento del mercado interno (1930-1973).

- Metropolización y replanteos urbano-territoriales durante la inserción global en clave neoliberal (1973-2002). Fases: Apertura comercial bajo el gobierno de facto (1973-1985) y Apertura comercial al retorno democrático (1985-2002).

- Conurbaciones y policentrismo con irrupción del agronegocio y nueva logística y nueva matriz energética (2002-2014). Fases: crisis y reactivación (2002-2005) y expansión económica bajo gobiernos progresistas (2005-2014). 


\section{PERIURBANO DESDE LA PERIFERIA}

Los estudios sobre los bordes urbano- rural cobraron protagonismo desde la década de 1940 cuando los procesos de suburbanización y metropolización en las ciudades norteamericanas, en un contexto de urbanización acelerada, impusieron una reflexión sobre estos novedosos episodios urbanos de la ciudad industrial de la posguerra.

Dentro del marco teórico, nos remitimos a desarrollos recientes del concepto de periurbano a través de Barsky (2005, 2013) y Hernández Puig (2012). Hardoy (1972), Romero (2001) y Pradilla Cobos (2014) aportan a identificar las particularidades de las ciudades latinoamericanas, en tanto el acervo de los Institutos de Historia (IHA) y de Teoría y Urbanismo (ITU) de la Facultad de Arquitectura de la UDELAR dan cuenta de las trayectorias de las ciudades uruguayas. También se consideraron otras concepciones contemporáneas sobre el borde urbano- rural como las que surgen de Indovina (2005) o Dematteis (1995) para las ciudades europeas.

Dentro de las primeras conceptualizaciones sobre periurbano, se destaca la identificación de una franja con usos múltiples entre lo rural y lo urbano que desafía la taxonomía urbano- rural y la zonificación funcional derivada de la ciudad planificada moderna.

H. Carter (1974) menciona que "El espacio hacia el cual se extiende la ciudad como resultado del proceso de dispersión ha creado el concepto de la franja rural-urbana, un área con características particulares, la cual ha sido solo parcialmente asimilada en el creciente complejo urbano y que sigue siendo en parte rural, ya que muchos de sus residentes viven en el campo, pero no dependen de él, ni social ni económicamente" (Carter, $1974 ; 323)$ y al identificar estudios acerca de los crecimientos en la ciudad norteamericana a fines de los años 60 , encuentra que "en los límites de la ciudad, en el contexto de la franja, es característico una gran mezcla de usos del suelo" (idem; 324).

Hernandez Puig (2012) refiere a que R. Colledge (1960) caracterizaba estas franjas de borde para las áreas metropolitanas, estudiando el caso australiano, considerando que en el espacio periurbano existe una pauta de ocupación del territorio en continuo cambio, con explotaciones agrícolas intensivas y de pequeño tamaño, población móvil y en baja densidad, dotación incompleta de servicios y equipamientos público y operaciones urbanas especulativas.

En los procesos de crecimiento de las ciudades anglosajonas durante el siglo $\mathrm{XX}$, las periferias comenzaron a tener una connotación como lugar de segunda residencia y luego de residencia de las clases altas. La valoración de los ámbitos por fuera de la contaminación y congestión de la ciudad, motivaron los modelos de la ciudad- jardín. Era una periferia planificada donde el modelo territorial implicaba una baja ocupación y la valoración de atributos ambientales y paisajísticos.

En Latinoamérica, las periferias tuvieron otro recorrido y significación, ya que: "ni el desarrollo capitalista en América Latina ni la urbanización que generó han seguido el mismo camino histórico ni iguales modelos, ni ocurrieron en los mismos tiempos y ritmos seguidos por estos procesos en Europa o Estados Unidos en los siglos XIX y XX" (Pradilla Cobos, 2014; 38).

Barsky (2005) coloca al periurbano dentro de nuevas configuraciones territoriales derivadas del neoliberalismo y pone acento en que "en los países latinos la ocupación del suelo en las áreas periféricas generalmente se realiza de una manera no planificada, constituyendo un espacio de gran heterogeneidad y crecimiento acelerado, donde pueden registrarse problemáticas sociales y ambientales agudas, un mercado del suelo poco transparente, proximidades conflictivas" y que constituye un "territorio de borde" "sometido a procesos económicos relacionados con la valorización capitalista del espacio, como consecuencia de la incorporación real o potencial de nuevas tierras a la ciudad" y cita a Garay (2001) cuando manifiesta que "sobre el borde periurbano se despliega un frente productivo que transforma el espacio rural en suelo urbano, donde la expectativa de valorización no necesariamente se realiza (..). Se trata de un área de transición, por la que atraviesa un proceso que supuestamente incorpora valor al territorio acondicionándolo para implantar nuevas actividades, pero a la vez como un proceso que se expresa -entre otras cosas- en la modificación de los patrones de asentamiento de la población".

Puede considerarse que en las últimas décadas, en las ciudades occidentales, comenzaron a darse, en un mundo posfordista, y cada vez más integrado, ciertos fenómenos con parámetros comunes dentro de una 
reestructuración territorial donde la interfase urbano- rural deja de ser conceptualizada en gradientes de intensidad de uso urbano casi en formato concéntrico hacia lo rural productivo intensivo, para pasar a esquemas multifuncionales complejos, con un protagónico papel de las periferias metropolitanas, superponiendo en espacios contiguos una multiplicidad de usos: equipamientos de consumo, distritos industriales y logísticos, grandes infraestructuras de transporte, nuevas formas de producción de espacio habitacional.

\section{TRAYECTORIAS DEL CRECIMIENTO URBANO}

\section{1- FUNDACIONES}

Las tardías ciudades coloniales de raíz hispánica en el actual territorio uruguayo tomaron las Leyes de Indias para su implantación y trazado (Álvarez Lenzi, 1986; 26). En la "ciudad- territorio" ser "poblador" implicaba suscribir un contrato y recibir tierras, exenciones impositivas y ayuda inicial a cambio de edificar casa y radicarse y cultivar la parcela. (Klaczco y Rial, 1981; 44). La ciudad era concebida unitariamente con su casco urbano y un territorio aledaño que le servía de sustento económico, defensa y ofrecía posibilidades de crecimiento y una jurisdicción, que contenía la zona rural adjudicada, en grandes extensiones, a los pobladores (Carmona y Gómez, 2002; 12).

A pesar de la dispar e incompleta aplicación de las Leyes de Indias en el territorio uruguayo, los centros urbanos coloniales tuvieron su casco urbano de damero regular, su ejido y zona de chacras.

En el pasaje al país independiente (1830), las ciudades fundadas por el Estado Uruguayo se restringieron al núcleo urbano propiamente dicho (manteniendo la formalización del damero regular) rodeado a veces de una pequeña zona rural fraccionada en chacras y quintas, que recibió la denominación de ejido. Allí, a través de donación o venta, el Estado dirigía el interés económico de los pobladores hacia los nuevos pueblos, ubicados en zonas poco atractivas pero en los que era necesario instalar enclaves para que el estado lograra un efectivo control sobre su territorio. (Alvarez Lenzi, 1986; 35). Si bien ambos ejidos, el colonial y post colonial tenían entre sus cometidos ser eventual asiento de crecimientos del poblado original, mientras el colonial era una zona enajenable en tanto no se lo desafectara de su función, vacío de construcciones y cultivos, el ejido post colonial estaba primordialmente afectado a la producción agrícola. El poblador de la era republicana, fue principalmente un comprador de tierra que si pudo se transformó a su vez en vendedor e incluso si pudo transformarse en especulador (Klaczco y Rial, 1981; 44).

Desde la década de 1870, la "modernización" productiva y política, implicó la inserción del Uruguay en el capitalismo mercantil mundial, desde un lugar periférico, agroexportador y dependiente. En 1876 el Presidente de facto Cnel. Latorre decretó que las tierras fiscales solo podían ser enajenadas por valor corriente fijado por tasación, y las tierras públicas dejaron de ser para el Estado un medio de promocionar una política poblacional, para convertirse en fuente de recursos presupuestales. (Klaczco y Rial, 1981; 45). La tierra urbana pasó a ubicarse claramente como una mercancía.

\section{2 CICLO: SISTEMA URBANO TRIBUTARIO DE LA MACROCEFALIA CAPITALINA}

\subsection{1: PRIMER BATLLISMO}

Uruguay inició el siglo XX con una impronta urbana (casi un 45\% de población urbana en 1908; en 2011 era $94,5 \%$ y macrocefálica (Klaczco y Rial, 1981). Este fenómeno se ha explicado principalmente por la poca y dispersa mano de obra requerida por la principal actividad productiva del campo: la ganadería.

El impulso urbanizador se alimentó de inmigrantes europeos con perfil mayormente urbano, aun cuando el Estado insistió (con magros resultados) en promover la colonización agrícola.

Del fraccionamiento de tierras vinculadas al tendido de la red ferroviaria nacional (con sus estaciones, galpones, $y$ talleres), desde fines del siglo XIX, surgieron una serie de pueblos que constituyeron un modo de urbanización propio de este ciclo del territorio (Martínez y Altmann, 2016; 18) y que no dispusieron en su trazado original de una zona de ejido o de chacras.

En las principales ciudades se dieron procesos de crecimiento dentro de las cuadrículas de la expansión de planteadas desde fines del siglo XIX y algunos loteos de nuevos barrios, así como algunas intervenciones urbanas puntuales que reflejaron en los espacios no metropolitanos, las características de lo que Romero (2001) Ilamó "La ciudad burguesa": "Al mundo todavía colonial fueron llegando los últimos ecos del ejemplo 
de Haussmann, melancólicamente traducido en una inmensa plaza desproporcionada o en un bulevar con plazoletas que conducía del centro de la ciudad a la estación del ferrocarril (...) quedó flotando en el ambiente como una vaga aspiración a proporcionar a cada ciudad provinciana algo que le permitiera creerse metrópoli" (Romero, 2001; 283)

En el ámbito de la ciudad proyectada, el Ministerio de Obras Públicas creó en 1911 la sección de Embellecimiento de Pueblos y ciudades, dirigida por el Arq. Raúl Lerena Acevedo, quien generó una serie de planes para las principales ciudades del interior, con rasgos pintoresquistas y de la ciudad jardín inglesa. Las propuestas (que no se llevarían a cabo) conjugaban el reordenamiento vial y creación de grandes avenidas y parques, muchos de los cuales funcionaban como anillos de borde del trazado urbano, al tiempo que en torno a los cursos de agua como arroyos se proponían parques lineales o canalizandos a cielo abierto. "El disciplinamiento que la urbanidad conlleva dentro del proyecto batllista necesariamente se traslada a todas las ciudades del país promoviéndose los planes de ensanche y embellecimiento como forma de trasmitir el crecimiento y desarrollo de lo urbano frente a lo rural" (Articardi, 2015; 85).

\subsection{2: MODELO DE SUSTITUCIÓN DE IMPORTACIONES, CRECIMIENTO URBANO, LOTEOS PARTICULARES Y NUEVA NORMATIVA}

Tras la crisis de 1929, Uruguay ingresó en un ciclo de desarrollo con protagonismo de la industria de sustitución de importaciones (ISI) y de fomento del mercado interno, que entrará en crisis en los años 1970. El modelo ISI no varió el esquema general agroexportador y ganadero extensivo, pero generó importantes resonancias urbano-territoriales particularmente fuera de Montevideo. La instalación de frigoríficos, textiles, industrias extractivas y medianos y grandes complejos de elaboración de alimentos y bebidas tensionaron hacia periferias, las tramas de las principales ciudades del interior uruguayo.

En éste período, se dejaron de fundar nuevas localidades en el país (salvo los balnearios que emergen desde la década de 1940) y se expandieron los centros existentes, particularmente las capitales departamentales, impulsadas por loteos de barrios por fuera de las cuadriculas regulares que caracterizaron los dameros fundacionales y primeras expansiones planificadas. El Estado también aportó a éstas dinámicas urbanas, favoreciendo el acceso a la vivienda a los sectores trabajadores con la ley Serrato (1921) y la creación del Instituto de Viviendas Económicas (1937).

Condicionantes topográficas y orográficas pautaron la localización de los nuevos espacios urbanos, en tanto la demanda de suelo urbano se incrementó y los espacios contiguos a las ciudades, presionados por la necesidad de urbanización, menguaron su protagonismo productivo en pos de ser reserva de tierra posiblemente urbanizable. Los crecimientos no fueron por lo general objeto de planificación urbana, sino más bién desde el fragmento, afectando la zonas "de huertos" con usos no productivos (industriales, o enclaves de hábitat precario). Estas carencias de planificación se dieron a pesar de que en la Facultad de Arquitectura existían cursos de urbanismo desde principios de la década de 1920, el Instituto de Urbanismo fuera creado en 1936 y Montevideo crear la oficina del Plan Regulador en 1933, experiencia que replicaron algunos pocos departamentos del resto del país.

La inversión estatal en provisión de servicios de agua y alcantarillado, la red de carreteras, el incremento de las capacidades de los gobiernos sub-nacionales a través de las reformas constitucionales de 1917, 1934 y 1942 y la sanción de la Ley Orgánica Municipal en 1935, aportaron al crecimiento de las principales ciudades del interior, que a su vez recibían una nueva oleada migratoria desde lo rural, donde en los "rancheríos" se apostaba la población desocupada, en condiciones de pobreza extrema.

La ley de centros poblados (1946) planteó una moderna legislación sobre la creación y expansión de ciudades, pero llegó tardíamente. Tomando en cuenta antecedentes higienistas y modernos planteaba la exigencia de (entre otros) disponibilidad de agua potable, y suelo de uso agrícola en el entorno inmediato, o considerar la altura de las máximas crecidas de los cursos de agua. También prohibió "toda división de tierras que implique crear predios independientes menores en superficie a dos mil metros cuadrados (2.000 m2), en cualquier centro poblado o zona urbana o suburbana, donde previamente no se hayan establecido servicios públicos de saneamiento y agua potable, o servicios privados de la misma índole que excluyan técnicamente la posibilidad de contaminación del suelo y de las aguas para el consumo" (Ley 10723. Art. 15).

La inobservancia de ésta ley fuera de Montevideo (por via de excepciones) en las décadas siguientes fue notoria respecto a la autorización de fraccionamientos sin estudios previos rigurosos o sin servicios de infraestructura, siendo determinante en la estructuración de las periferias en los siguientes períodos. 


\section{3: EL PERÍODO DE ANÁLISIS: RECONFIGURACIÓN DE PERIFERIAS EN DOS CICLOS: APERTURA NEOLIBERAL Y PROGRESISMO (1973-2015)}

La ciudad sudamericana que surgirá luego de los procesos de industrialización tardía y desindustrialización temprana, será de urbanización acelerada, autoconstrucción de vivienda popular en terrenos ocupados, programas públicos de vivienda en periferias frágiles, barrios exclusivos de altos ingresos en enclaves semi rurales.

En el ciclo de desarrollo a partir de la década de los 70, (apertura comercial y neo-liberalismo en el marco de la globalización), el Uruguay urbano se caracterizó por el agotamiento de las migraciones rural - urbana y el comienzo del protagonismo de los flujos urbano- urbano. Montevideo consolidó su área metropolitana, con desbordes de informalidad y precariedad urbano- habitacional en sus periferias, asociadas a migraciones de desocupados del interior y la expulsión de población de sus áreas centrales.

Las ciudades medias se involucraron en procesos regionales agroindustriales, con influencia de la teoría de los polos de crecimiento: caña de azúcar y derivados, arroz, industria lechera, en primera instancia con destino al abastecimiento interno. Luego apareció la forestación exótica (eucaliptus, pinos) y en la última década la soja y otros cultivos extensivos, con nuevos formatos de gestión de un negocio agropecuario cada vez más desterritorializado. También se consolidó un pujante sector de servicios sobre la costa, encabezado por Maldonado-Punta del Este, que en 1963 era una de las capitales departamentales con menor población, con 15000 personas, y en 2011 con casi 110.000 habitantes, se posicionó como el segundo aglomerado urbano del país.

Las CIU mostraron un crecimiento poco controlado, a influjo de fraccionamientos privados (loteados durante décadas sin servicios básicos, haciendo caso omiso a la Ley de Centros Poblados). La carencia de planes urbanos consistentes para guiar los crecimientos, el desarrollo infraestructural de agua y saneamiento definido a nivel central por Obras Sanitarias del Estado de forma desarticulada a los proyectos urbanos de las ciudades (Cutinella, 1964; 69), la construcción de bloques viviendas económicas del estado y posteriormente de conjuntos cooperativos (Ley de vivienda, 1967) en terrenos periféricos para abaratar costos desde un emplazamiento en suelo rústico, apuntalaron el desmembramiento periférico de las principales capitales del país. A su vez, los gobiernos departamentales, ávidos de recursos genuinos (en promedio la mitad del presupuesto de la intendencias departamentales es solventado con transferencias directas del gobierno nacional) propiciaron categorizar suelos con carácter urbano o sub urbano para aumentar su capacidad de captar tributos por contribución inmobiliaria, no solo porque el suelo urbano o sub urbano por su mayor intensidad de uso tributa más que el rural, sino porque la contribución inmobiliaria rural en Uruguay es recaudada centralmente por el gobierno nacional.

\section{CLAVES TERRITORIALES EN LOS CASOS DE ESTUDIO}

Para este primer acercamiento a los fenómenos de reconfiguración de bordes urbano- rural se usaron como fuentes: fotos aéreas (1966- 2016), datos censales INE, los planes locales urbanos y de ordenamiento territorial de Salto y Florida y el acervo del equipo de Ciudades Intermedias del Instituto de Teoría y Urbanismo de la FADU- UDELAR y los expedientes urbanos realizados por el Instituto de Historia de la Arquitectura de la FADU- UDELAR en la década de 1960. 


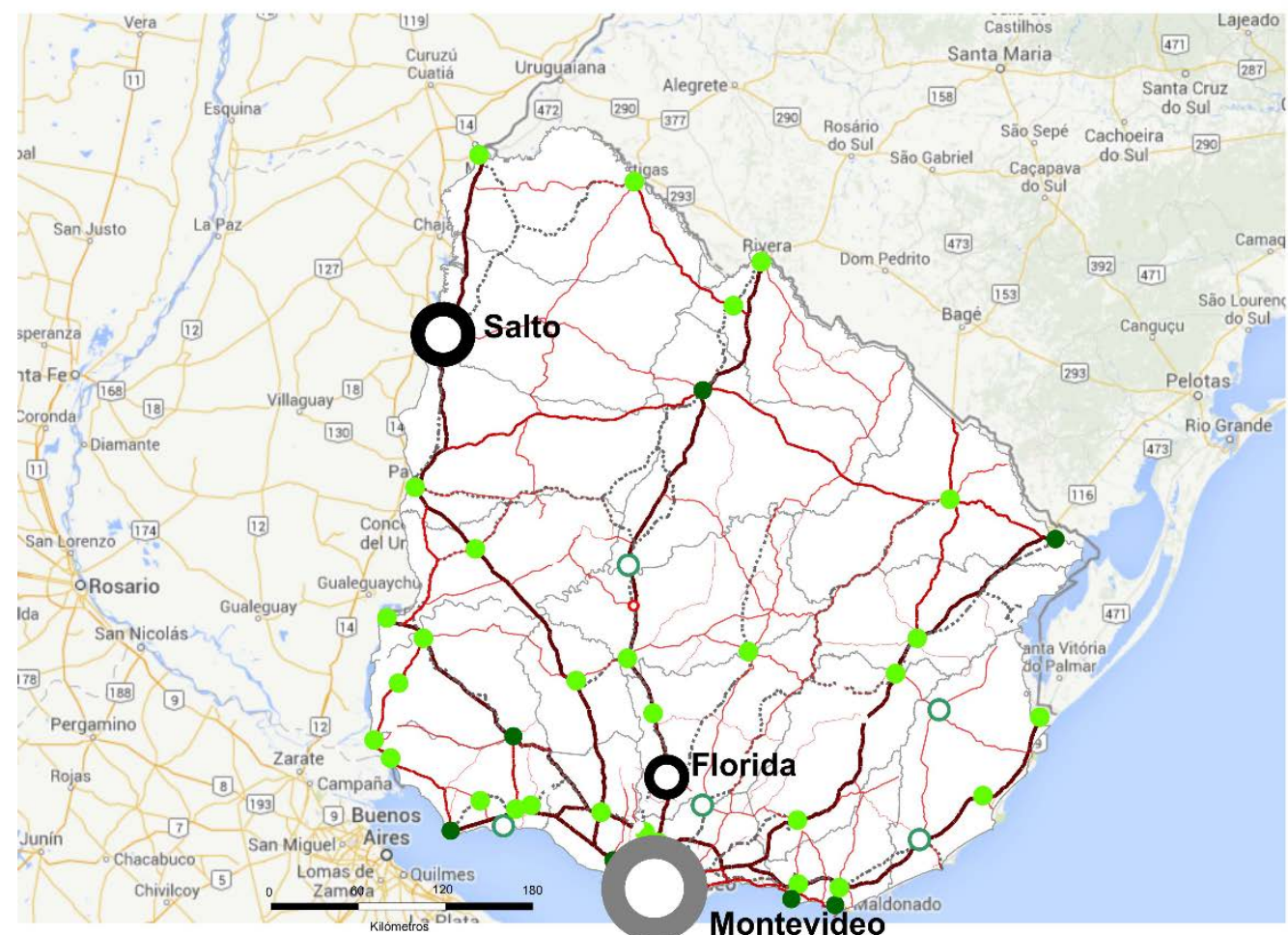

Imagen 03: ubicación de Salto y Florida en Uruguay y la región.

Fuente: Elaboración propia en base a cartografía Google maps, y cartografía INE Uruguay.

\section{1- FLORIDA: PERIURBANIZACIÓN LEVE PERO SIGNIFICATIVA}

Florida pasó de 21.000 habitantes en 1963 a casi 34.000 en 2011 . En el lapso 1985- 2011 tuvo una tasa de crecimiento promedio anual de $0,64 \%$, menor a la del país urbano $(0,71 \%)$.

Fue la última ciudad fundada por los españoles en la Banda Oriental (1809), sede de la declaración de independencia de Uruguay (1825). En la era republicana, pasó a ser capital del creado departamento del mismo nombre (1856). En 1874 el ferrocarril llegó a la ciudad, sobre la vía fundacional del trazado ferroviario uruguayo. Según los criterios de mayor rentabilidad utilizado por las empresas inglesas constructoras del ferrocarril, las estaciones en las ciudades existentes se ubicaron al borde de las tramas. De esta forma, y por su emplazamiento en una elevación en un recodo del río Santa Lucía, Florida embretó su crecimiento entre la vía del tren y el río.

1809

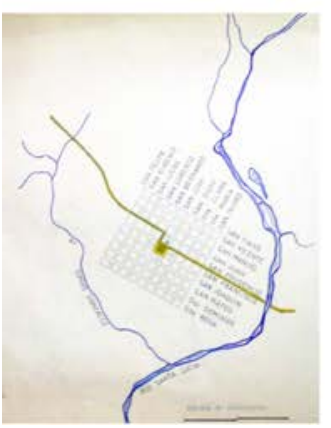

1855

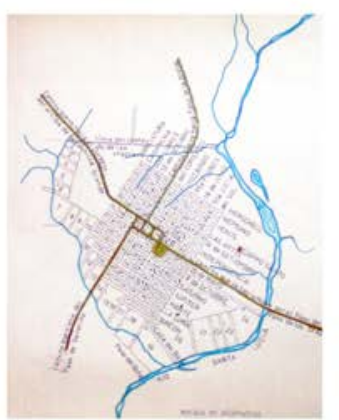

1880

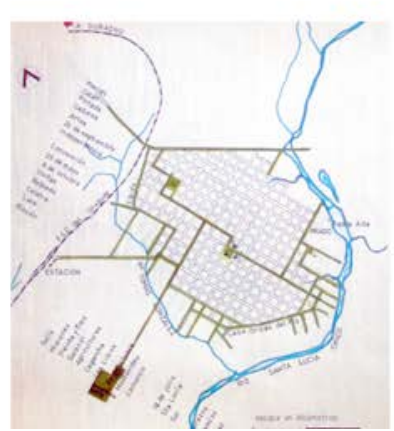

1940

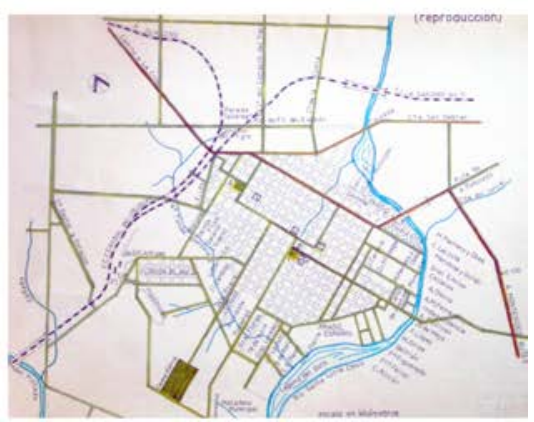

Imagen 04: Evolución de la planta urbana de Florida hasta mediados del siglo XX.

Fuente: Instituto de Historia de la Facultad de Arquitectura de la UDELAR (1969).

La estación de ferrocarril direccionó las primeras "tensiones" hacia fuera de la trama fundacional. A principios del siglo XX el fraccionamiento "Floridablanca" (contiguo al hipódromo, establecido en 1885) "cose" la zona de la estación con el damero histórico. 
La fundación de la Cooperativa Nacional de Productores de Leche- CONAPROLE (1937) será clave en el desarrollo regional, al instalarse una de sus plantas de procesamiento de lácteos en el entorno de la ciudad, convirtiéndola en epicentro de la principal cuenca lechera del país. Luego de 1950 Florida "salta" sobre la vía férrea, avanzando sobre el viejo ejido. Los fraccionamientos se suceden, sin un criterio general de ordenación, particularmente en las zonas oeste y norte.

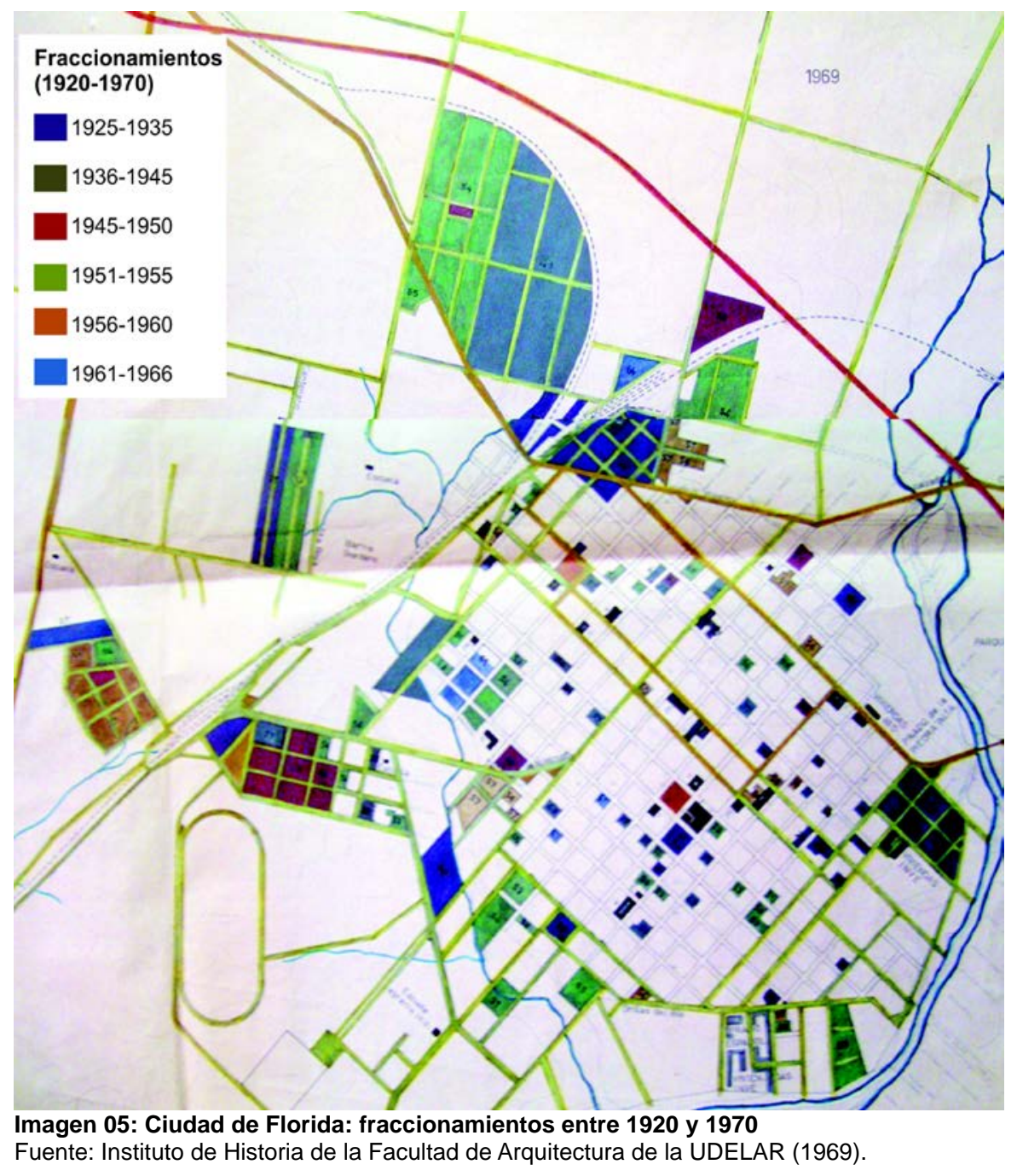

En estas expansiones primó la provisión parcial y ex-post de los servicios básicos de infraestructura urbana (Saneamiento, pavimentos, escurrimiento de aguas superficiales, alumbrado público).

Entre 1985 y 2004 la ciudad sumó casi 100 hectáreas (creció un 25\% en superficie) de ocupaciones urbanas mayores a 4 viviendas por hectárea, pero aumentó su población en 12 \%. (Martínez, 2007-2015). 


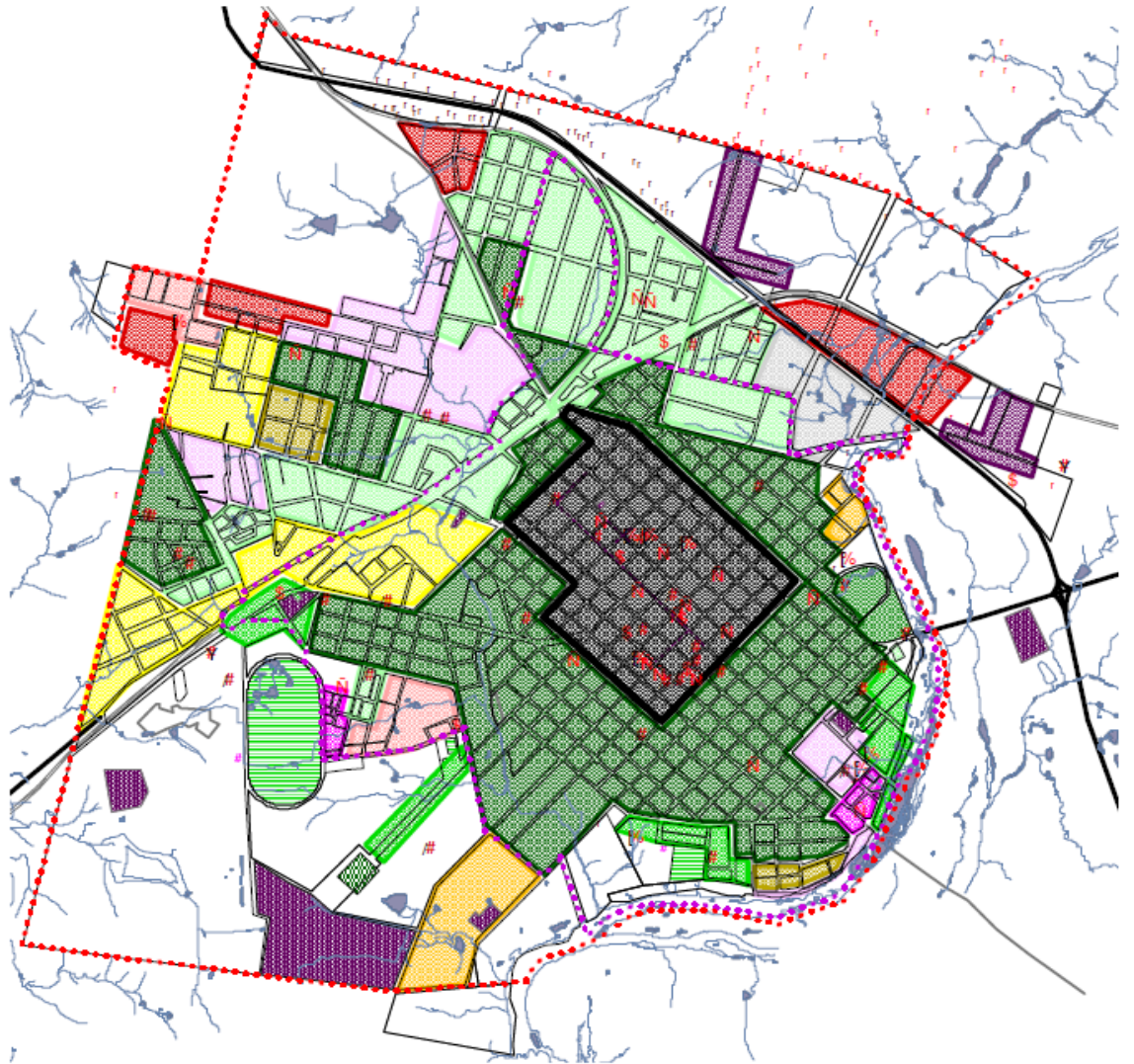

Imagen 06: Variantes de acondicionamiento infraestructural en Florida (2005) Fuente: Martínez (2007-2015).

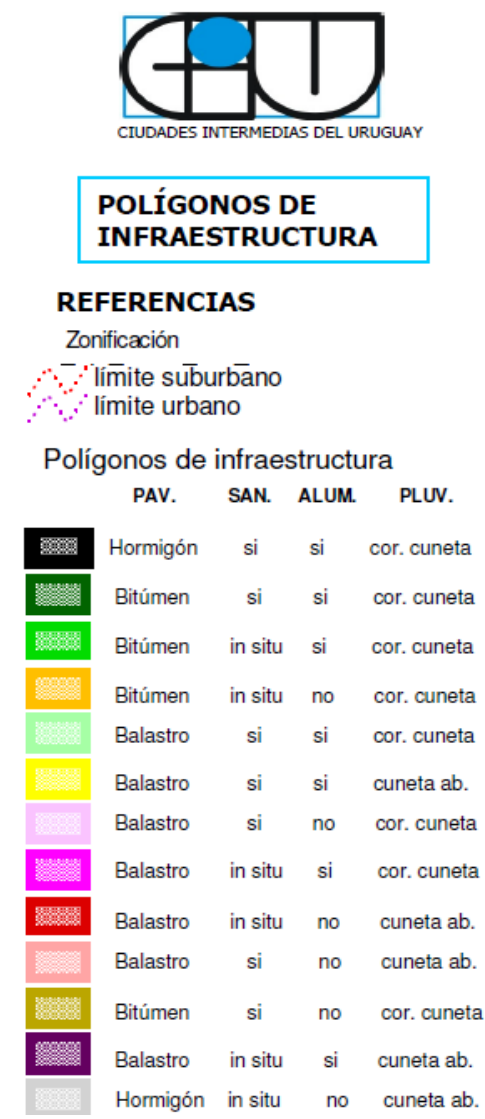

Recientemente comenzó a prefigurarse una periferia más heterogénea. A la expansión formal se sumaron seis asentamientos precarios surgidos entre 1996 y 2004 (el mayor de ellos, fue realojado en 2014) y enclaves industriales o logísticos. En 1989 en la zona suroeste se estableció una empresa de lavado y peinado de lana; en 1993, al sur de la ciudad se instaló, en un predio de 20 hectáreas, la primer zona franca del interior del país. El frigorífico, situado las afueras de la ciudad y la planta industrial de Conaprole (lácteos), son de etapas anteriores a 1985.

También aparecieron nuevos barrios en baja densidad y entorno rural, hacia el este (ruta 56), cerca de los cuales se instaló recientemente un parque de energía eólica.

1966

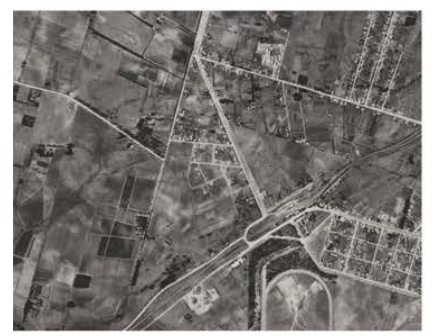

1981

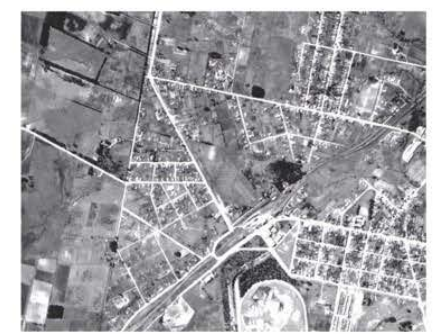

1995

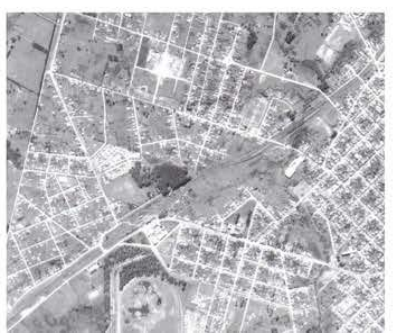

2015

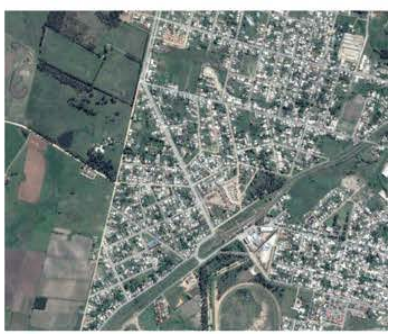

Imagen 07: Proceso de ocupación de borde oeste de Florida, 1966- 2016.

Fuente: Servicio Geográfico militar (1966, 1981, 1995) e imagen Google Earth 2016.

En resumen, los territorios periféricos de Florida desde la década de 1970, donde se suceden enclaves en entornos semi rurales: industria y logística, episodios de informalidad y precariedad urbana concentrada, conjuntos habitacionales públicos y barrios en entornos no urbanos y en amplios predios para sectores altos, han dado lugar a una periferia desarticulada. 


\section{2 - SALTO: PERIURBANO INVERTIDO}

Salto, llegó a los 105.000 habitantes en 2011, en tanto en 1963 tenía 58.000 pero ya era la segunda ciudad del país. En el período 1985- 2011, creció al 0,99 \% de tasa promedio porcentual anual, superando la tasa del país urbano $(0,71 \%)$ y del conjunto de las ciudades intermedias $(0,94 \%)$, colocándose entre los centros poblados de mayor dinamismo demográfico en ese lapso.

Salto fue una de las pocas ciudades de la era colonial uruguaya no surgida por resolución de la corona española. Con el antecedente de un fuerte español de mediados del siglo XVIII, el último puerto y paso del río Uruguay antes de las cascadas (saltos), se convirtió en un enclave estratégico militar, luego de que Artigas instalara su campamento revolucionario allí en 1811. Los portugueses establecieron una fortificación con una guarnición, alrededor de 1820, la cual floreció como agrupación de población en torno al comercio de tránsito. Designada capital del departamento con su nombre creado (1837), el trazado de la ciudad fue ampliado por el estado en 1869 al declararla ciudad. Su temprana incorporación a la red ferroviaria (1872), como cabecera de una línea a las ciudades de Artigas y Bella Unión, limítrofes con el Brasil, muestra el rol de Salto como nodo multimodal del comercio de la época, en clave de triple frontera: transporte fluvial hacia Buenos Aires y Montevideo vía Río Uruguay y terrestre (hacia el Brasil) por los pasos de Bella Unión y Artigas.

Al llegar el siglo XX, a la ciudad llegaban cientos de inmigrantes y se desarrollaban el cultivo de la vid y la naranja. La condición de enclave agroproductivo, su prominente actividad industrial (saladeros, astilleros), y comercial por ser puerto, dieron a Salto un desarrollo que rápidamente la colocó como la segunda ciudad del país.

Promediando el siglo XX, la etapa de sustitución de importaciones, llevó a la ciudad a continuar su crecimiento: "Sin plan regulador la ciudad creció como pudo, embretada por los dos arroyos laterales que desembocan en el Uruguay, que se hinchan con éste, y la invaden por los costados en tiempos de crecientes. Sólo en la década del cincuenta, Salto pudo saltar esos bretes y extenderse plenamente sobre el rio (...) Los barrios se fueron sucediendo unos a otros, antes y después de la luz, el agua o el ómnibus, sin que importara mayormente si existían o no dichos servicios".(Nuestra Tierra b, 1970; 9).
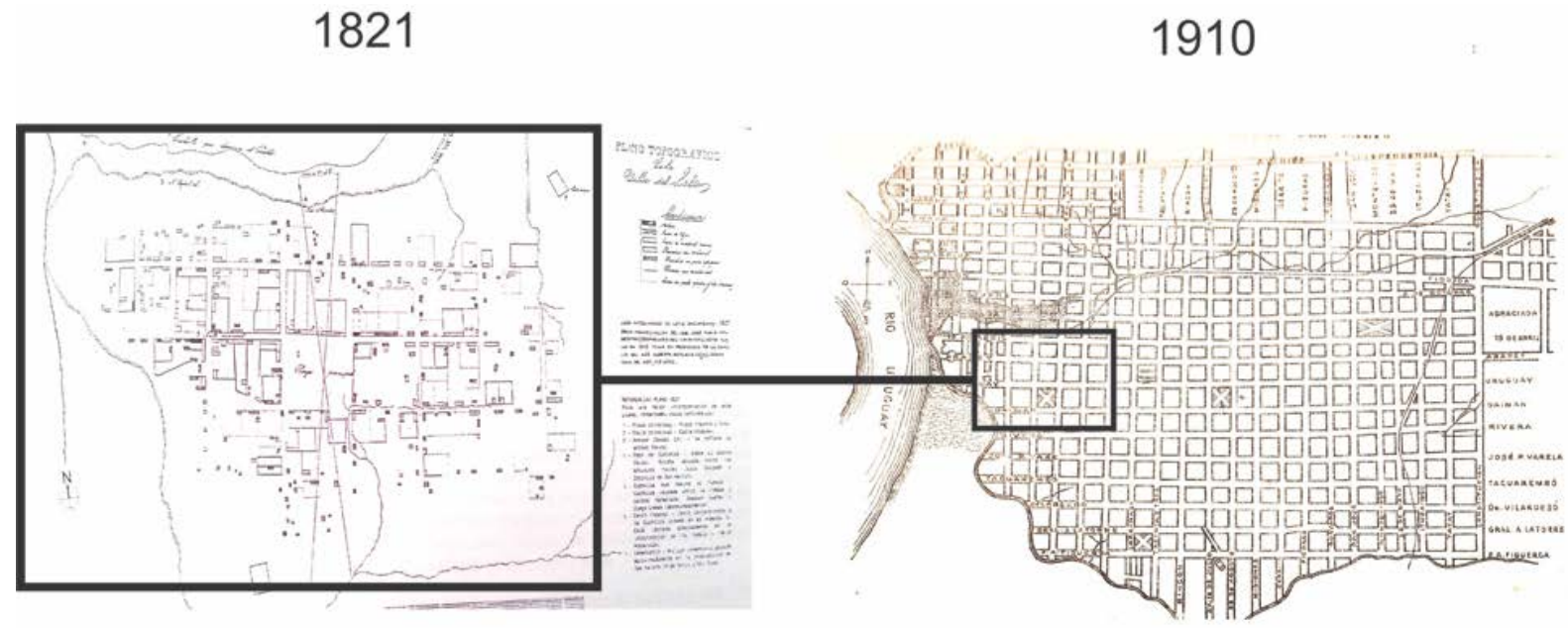

Imagen 08: Mapas de Salto en 1821 y 1910.

Fuente: Musso (2004) 


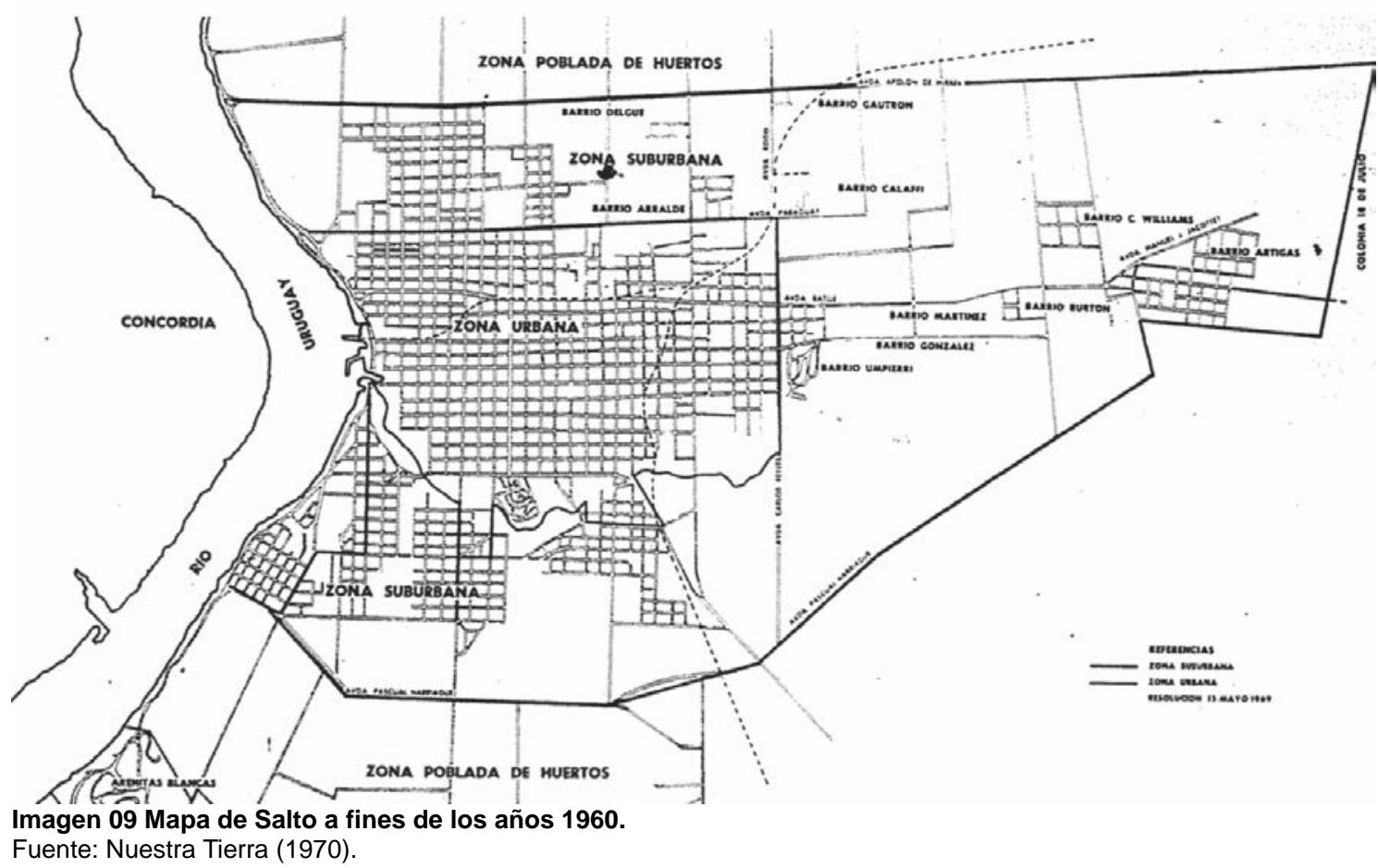

Tras la crisis del modelo ISI, la ciudad presenció la construcción entre 1979 y 1983 del complejo hidroeléctrico binacional de Salto Grande y el descubrimiento de aguas termales en torno a los ríos Arapey y Daymán. El último, cercano a la ciudad menos de $10 \mathrm{~km}$, dio lugar a un enclave turístico termal, que dio a Salto de un interesante sector de servicios.

Sobre los usos del suelo en la periferia y la interfase urbano-rural, deben señalarse tres hitos normativos: zonificación de 1969 y planes urbanos de 1998 y 2016. La primer normativa, estableció el área urbana, sub urbana y la "zona poblada de huertos". El Plan de 1998, marcó entre sus cometidos "el mantenimiento de los limites urbanos actuales a fin de impedir la ocupación de áreas productivas con fraccionamientos destinados a viviendas y otras actividades de tipo urbano" (IDS, 1998; 8) y "apoyar la permanencia del pequeño y mediano productor hortifrutícola manteniendo ese modelo de ocupación (20 hab x km2) que responde a un tipo y sistema productivo de base familiar y alta ocupación de mano de obra" (idem). Se mantuvieron los generosos límites urbanos de zonificación de 1969, consolidado el espacio de "huertos" al norte y sur de la ciudad y el establecimiento de "unidades de reserva" definidas como "áreas hacia donde no es conveniente expandir la ciudad debido a la conformación geográfica no favorable para la urbanización. Estas áreas desempeñarán un importante rol separando y consolidando unidades barriales existentes, afirmando bordes y evitando efectos de conurbación bajo malas condiciones de calidad ambiental. No se autorizarán los fraccionamientos menores a una hectárea" (IDS, 1998; 16). Las zonas de huertos "serán conformadas por solares que tengan como mínimo una hectárea de extensión, de conformidad con la ley de centros poblados" (idem, 19).

El recientemente aprobado Plan Local de Salto y su microrregión (IDS, 2016) mantiene el énfasis en controlar la expansión urbana y la puesta en valor de la zona de huertos definidos como "ámbitos territoriales de alta definición explícitamente así denominados en el planeamiento local y reconocidos a nivel social, con un perfil productivo, ambiental y paisajístico singular, con un carácter rur - urbano y con diversas mixturas de suelo" (IDS, 2016; art. 7) y potenciar el Cordón Hortifrutícola de la ciudad, apoyando la permanencia residencial de sus pequeños productores, o fortaleciendo los centros poblados microrregionales. En tanto se reconoce la presión urbanizadora al liberar como suelo categoría urbana un sector de la ex zona de reserva del Alto Ceibal e incorporar en la ex zona de huertos al norte, la posibilidad de uso residencial en régimen de urbanización en propiedad horizontal. 

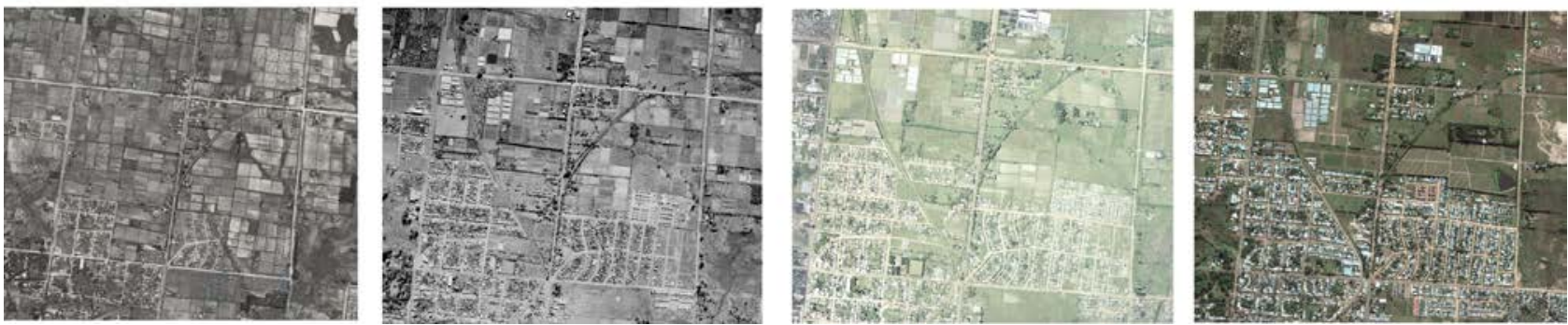

Imagen 10: Proceso de ocupación en el límite urbano- sub urbano, al norte de la ciudad de Salto, desde 1966.

Fuente: Servicio Geográfico Militar $(1966,1994)$ y Google Earth $(2005,2016)$.

Salto ha controlado la expansión urbana por fuera de límites urbanos o sub urbanos, en las últimas décadas. La amplia superficie categorizada como urbana, (más allá de sus variantes de consolidación), permite aún amortiguar el crecimiento demográfico. La problemática de aguas urbanas,(río Uruguay, arroyos Sauzal y Ceibal), es determinante en la conformación de las zonas de borde, particularmente al este de la ciudad. La ex "zona de reserva Alto Ceibal", por su potencial inundabilidad, genera una importante discontinuidad en la trama. Del otro lado de la "zona de reserva", barrios alejados, han sido destino histórico de viviendas de realojos de inundados. Ésta zona, de infraestructura incompleta y carencia de servicios ha visto crecer en la última década varios asentamientos irregulares ocupando terrenos municipales.
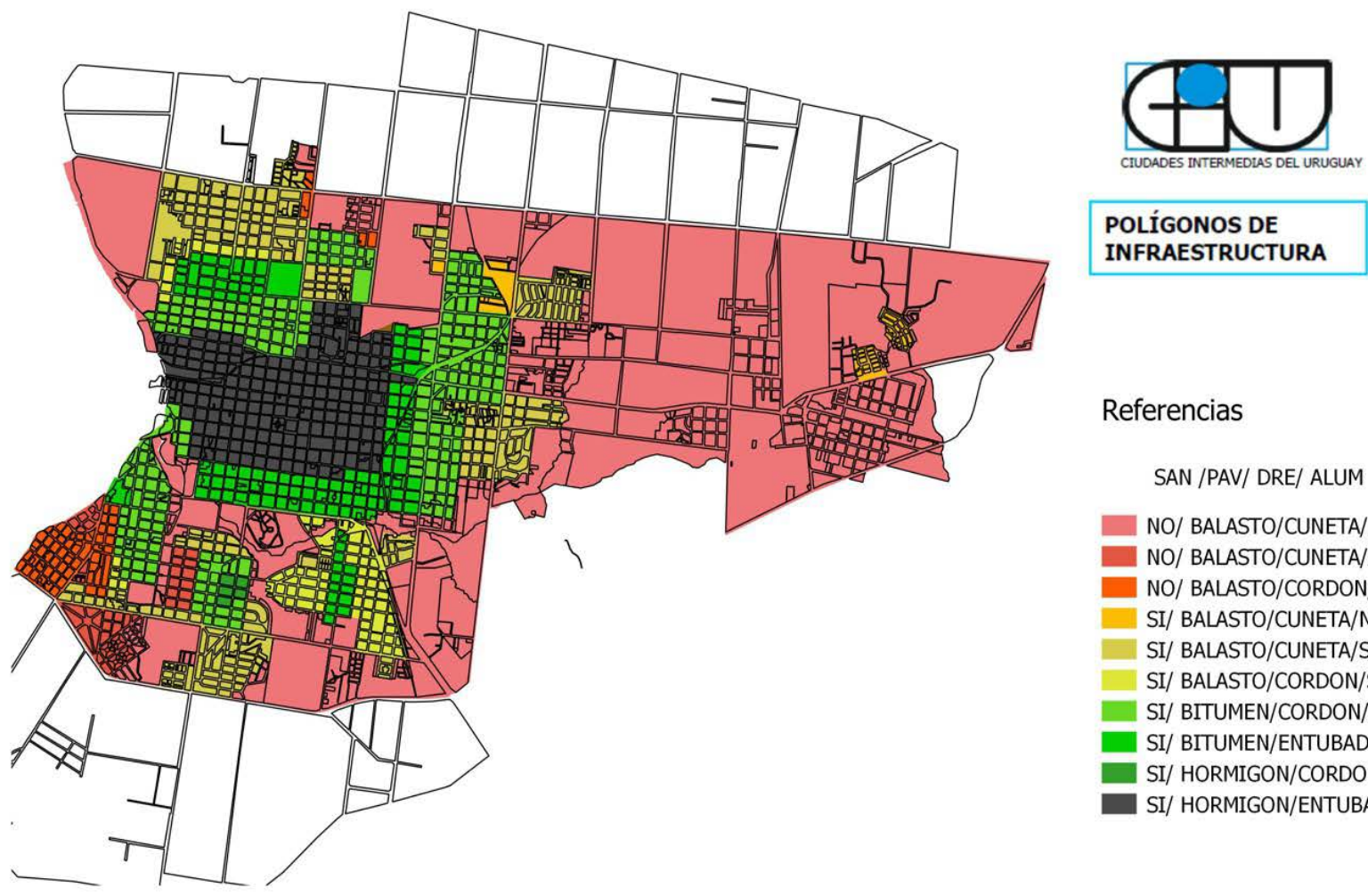

\section{POLÍGONOS DE \\ INFRAESTRUCTURA}

Imagen 10: Variantes de acondicionamiento infraestructural del suelo en Salto (2005)

Fuente: Equipo Ciudades intermedias del Uruguay (inédito, 2016).

La actual periferia salteña muestra sus mayores dinámicas en cambios de ocupación dentro de los límites de suelos urbanos o suburbanos. Los barrios surgidos desde los años 1950 son los más rezagados en la infraestructura, particularmente los del sur, en tanto en la zona este, el polo de crecimiento reciente se mostraba hasta 2005 sin servicios, salvo un conjunto de viviendas de realojo de inundados de la década de 1980 que fue provisto solamente de saneamiento.

Dentro de la zona "urbana" aún se dan infiltraciones productivas en una escala que no es de subsistencia ni agricultura familiar de autoconsumo, sino para volcar al mercado. La activación de usos habitacionales en el suelo categorizado "urbano" pero que estaba sin desarrollar, particularmente en la zona Este, muestra nuevos 
fraccionamientos formales, asentamientos irregulares, conjuntos habitacionales públicos de realojo de inundados, con contigüidad espacial pero sin una lógica ordenadora en lo morfológico ni en la provisión de infraestructura y servicios.

\section{7- REFLEXIONES PROVISIONALES Y PROXIMOS PASOS}

"Los patrones de estructuración urbana en América Latina están determinados, en forma compleja, por las lógicas de formación de las rentas del suelo urbano tanto en los territorios periurbanos como intersticiales metropolitanos como en áreas ya integradas donde se articulan las viejas y nuevas condiciones estructurales de la acumulación de capital" (Pradilla Cobos, 2014; citando a Jaramillo, 2009).

Las ciudades latinoamericanas no son solo sus populosas metrópolis. El protagonismo de las ciudades intermedias viene de anteriores ciclos históricos: las migraciones rural-urbano, por "descomposición de las formas atrasadas de producción agrarias y la carencia de servicios" (Pradilla Cobos, 2014; 41), la sustitución de importaciones y su urbanismo de industrialización, y las perspectivas desarrollistas de los complejos agroindustriales dinamizadores de economías regionales. Luego, los procesos de descentralización, tanto en su vertiente de izquierda (los beneficios de la participación y el poder local) como derecha (achicamiento del estado, traslado de responsabilidades del estado central) encontraron en los espacios subnacionales (gobernados o articulados en torno a ciudades intermedias), una oportunidad. Simultáneamente, la "problematización" a nivel global sobre las grandes concentraciones urbanas, derivó en la valoración de la escala de la ciudad intermedia, como "contrapeso" a las grandes metrópolis. (ONU, 1992).

Las ciudades intermedias de Uruguay crecieron lenta pero persistentemente, con las particularidades reseñadas. Sus bordes deben ser leidos, más allá del "continuo urbano-rural" conceptualizado por Sorokin y Zimmerman en 1929, y la dicotomía rural- urbano, en clave de "nueva ruralidad" incorporando una perspectiva diacrónica y compleja de un territorio multifuncional.

En las últimas décadas, en la cuenca del plata, la "diversificación de los actores productivos, flexibilidad del capital, simplificación tecnológica generan espacios de producción que van perdiendo virtudes territoriales (proximidad socio espacial, manejo económico, construcción política y gobernanza local) en beneficio de conformaciones socio-espaciales más débiles y atravesadas por fuerzas globales que las reestructuran" (Guibert et al, 2011; 13).

Las ciudades medias se han reposicionado por los cambios de un medio rural que urbaniza su fuerza de trabajo y requiere de un asiento urbano para la logística, servicios e insumos del agro. Estos procesos, "reescriben" (siguiendo a Corboz, 2005) sobre las huellas de un viejo ejido colonial que nunca llegó a consolidarse como tal, generando un "periurbano" entendido de modo amplio como una interfase rural-urbano con múltiples actividades en formato archipiélago asociada a la etapa actual de capitalismo.

Tras la experiencia de la inobservancia de la Ley de Centros Poblados (1946), la Ley de Ordenamiento Territorial y Desarrollo Sostenible - LOTDS (2008) marcaría un punto de inflexión dentro de los procesos tendenciales de ocupación del suelo, estableciendo que los instrumentos de ordenamiento territorial "son de orden público y obligatorios (y) sus determinaciones serán vinculantes para los planes, proyectos y actuaciones de las instituciones públicas, entes y servicios del Estado y de los particulares" (Ley 18308, Art. 2).

La LOTDS establece que el suelo puede categorizarse en: a) urbano en sus variantes consolidado y no consolidado, b) suburbano -planteado como enclave con diferentes usos y no como un espacio de transición entre rural y urbano- y c) rural -en su variantes natural y productivo. Éstas categorías plantean rigideces pero también flexibilidades, al incorporar el atributo de potencialmente transformable de una categoría a otra (debe plantearse específicamente a qué entidad territorial se le asigna tal calidad y hacia qué categoría puede transformarse, para lo cual debe efectuarse un Plan de Actuación Integrada).

El Plan local de Florida (2014) y el de Salto (2016), actualmente vigentes, plantean diferentes estrategias respecto al proceso de periurbanización. Florida apuesta a consolidar como urbanas las recientes expansiones y mantener como potencialmente transformable de rural a urbano una franja al oeste que consolidaría ese borde, manteniendo como "suburbano" los anteriores enclaves industriales, periféricos y residenciales, y reconociendo la "zona de chacras" cerrando el borde norte. (Imágen 12) 
En Salto, la propuesta (Imágen 11), se hace cargo de la complejidad del territorio, buscando consolidar el suelo urbano (queda categorizado, con variantes, como urbano todo el suelo que era suburbano en el Plan de Salto de 1998) eliminando las "zonas de reserva" pasando a ser "urbano no consolidado con alta sensibilidad ambiental". El uso suburbano se dirige hacia lo logístico en el borde sur y de residencia y recreación en la zona norte y se reconocen los atributos paisajísticos de los naranjales con corredores que serán objeto de manejo especial. La ex "zona de huertos" al sur se establece con régimen general de rural productivo y en la norte con régimen de potencialmente transformable a habitacional en régimen de urbanización en propiedad horizontal (baja densidad, parcelas de mínimo 1 hectárea).

El periurbano no es una categoría de suelo especificada en la Ley de Ordenamiento Territorial. Pero el "control" de éste fenómeno parece darse a través tanto de la caracterización como suelo urbano no consolidado, para "dirigir" la expansión de la trama consolidándola al dotarla de infraestructuras; o suburbano, manteniendo lógicas de enclaves con diferentes usos. El atributo de "potencialmente transformable" deja "en espera" las posibles transformaciones orientadas.

Para continuar el análisis de estos procesos es necesario establecer dimensiones e indicadores referente a superficie según usos del suelo en el período de estudio por lectura de foto aérea geolicalizada; el seguimiento de los cambios en normativa y autorizaciones y excepciones de usos del suelo y las estrategias de provisión de infraestructuras. También es necesario profundizar en la caracterización socioeconómica de los pobladores de las nuevas periferias y la secuencia de provisión de servicios, equipamientos, o espacios públicos y, particularmente para el borde peri urbano, los usos productivos del suelo. La lectura territorial implica un esfuerzo por captar estas distintas dimensiones que comparten una misma entidad territorial.

Los espacios de transición urbano- rural, acumulan el sedimento y las trazas de las anteriores configuraciones y se enfrentan a la inédita experiencia de una nueva gestión territorial que haga de los instrumentos de ordenamiento territorial verdaderas agendas de transformación y uso del territorio, con vocación democrática y de sostenibilidad ambiental; y no meras declaraciones de intenciones sin implicancias en el terreno.
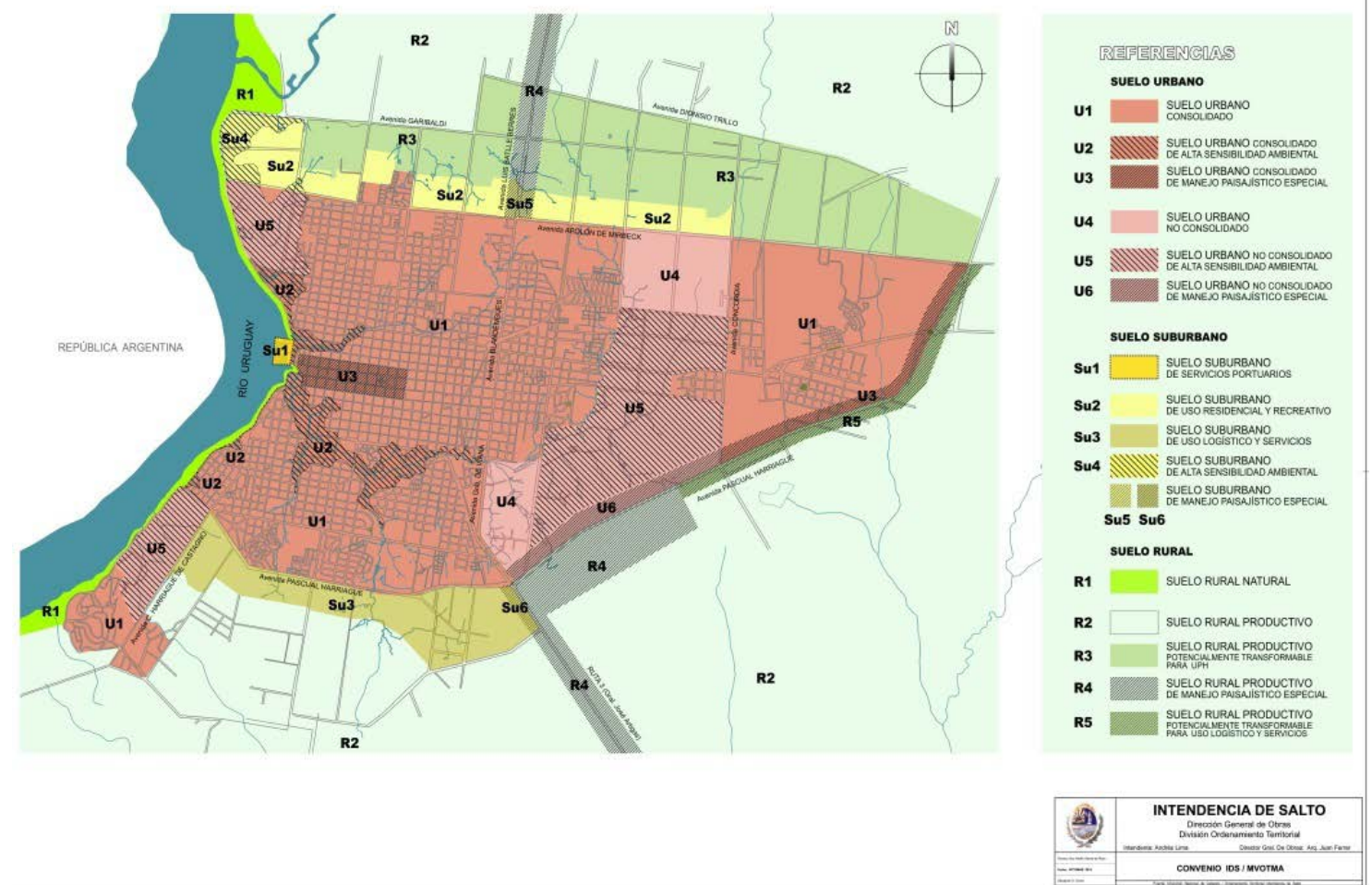

Imagen 11: Categorización del suelo según Plan Local de Salto, 2016. 


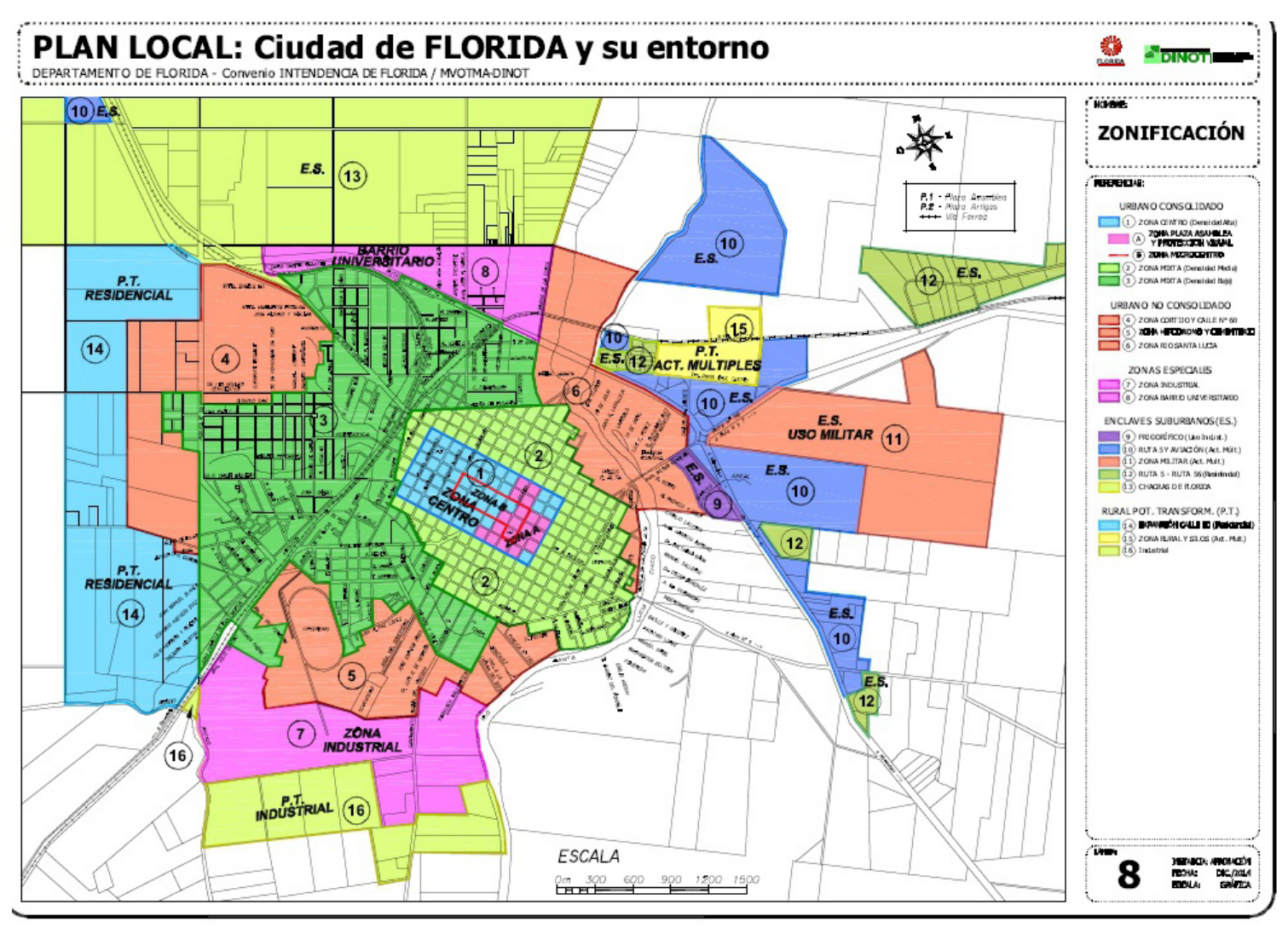

Imagen 12: Categorización del suelo según Plan Local de Florida, 2014.

Fuente: Intendencia Departamental de Florida.

\section{BIBLIOGRAFÍA}

\section{Obra completa:}

ALVAREZ LENZI, Ricardo (1986); "Fundación de poblados en el Uruguay", Montevideo. Instituto de Historia de la Arquitectura, Facultad de Arquitectura, Universidad de la República.

ARTICARDI, Juan A. (2015) "Dilemas Modernos: el proyecto urbano en Montevideo y la Costa Balnearia". Montevideo. UCUR CSIC UDELAR.

BELLET, Carmen; y LLOP, Josep Maria (2003) "Ciudades intermedias: perfiles y pautas; segunda fase del Programa CIMES: Ciudades Intermedias y Urbanización Mundial". Lleida, Ajuntament de Lleida/Pagès Editors.

CAPANDEGUY, Diego (2002): "Uruguay y sus territorialidades rurales contemporáneas". Paper de la Maestría en Ordenamiento Territorial y Desarrollo Urbano. Multicopiado.

CARMONA, Liliana y GÓMEZ, Leonardo (2002); "Montevideo, proceso planificador y crecimientos". Montevideo. FADU- UDELAR.

CARTER, Harold. (1974) El estudio de la Geografía Urbana. Madrid: Instituto de Estudios de Administración Local.

DINOT - Dirección Nacional de Ordenamiento Territorial (1997). "Anteproyecto de directrices nacionales de ordenamiento territorial". Montevideo. MVOTMA.

KLACZKO, Jorge y RIAL, Juan. (1981), Uruguay: el país urbano, Ediciones de la Banda Oriental, Montevideo. 
HARDOY, H. (1972) "Las ciudades en América Latina. Seis ensayos sobre la urbanización contemporánea". Buenos Aires: Paidós.

INSTITUTO DE HISTORIA DE LA ARQUITECTURA- FADU- UDELAR (1970) Expediente de la ciudad de Florida.

LEFEBVRE, H. (1968), El derecho a la ciudad, Ediciones Península, Barcelona.

MARTINEZ, Edgardo J, y ALTMANN MACCHIO, Leonardo (2016): "Entre la macrocefalia estructural y el policentrismo emergente. Modelos de desarrollo territorial en el Uruguay (1908-2011)". Biblioteca Plural CSIC - UDELAR, Montevideo.

MUSSO, Carlos (2004). "Las ciudades del Uruguay: su origen, evolución histórica y urbanística en el contexto nacional y macro regional y sus perspectivas de futuro". FARQ - UDELAR, Montevideo.

(2005): "Las escalas optimas de gestión para el territorio uruguayo. Definición de criterios para su articulación e instrumentación". Montevideo. Serie Cuadernos del Territorio. DINOT- MVOTMA- FADU UDELAR

NUESTRA TIERRA (1970) Serie Los Departamentos: Florida. Montevideo. Nuestra tierra.

Serie Los Departamentos: Salto. Montevideo. Nuestra tierra.

ONU- (1992) Agenda 21.

ROMERO, JOSÉ LUIS (2001): "Latinoamérica, las ciudades y las ideas". Ed. Siglo Veintiuno. Buenos Aires.

VAPÑARSKY, Cesar y GOROJOSKY, Nestor (1989): "El crecimiento urbano en la Argentina" Buenos Aires. Grupo Editor Latinoamericano

URRUZOLA, J.P. (editor) (2011) "La forma de las ciudades uruguayas" Montevideo. MVOTMA, Junta de Andalucía, AECID.

\section{Ponencias en eventos:}

ALTMANN MACCHIO, Leonardo (2017) "Entre macrocefalia estructural y policentrismo emergente. Modelos de desarrollo territorial del Uruguay". XXXI Congreso ALAS. Montevideo, 6 al 9 de diciembre de 2017. Disponible en http://alas2017.easyplanners.info/opc/t//0799 leonardo daniel altmann macchio.pdf

\section{Capítulos de libros:}

BARSKY, Andrés (2013), "La agricultura de 'cercanías' a la ciudad y los ciclos del territorio periurbano. Reflexiones sobre el caso de la Región Metropolitana de Buenos Aires", en Ada Svetlitza de Nemirovsky (Coord.), Globalización y Agricultura Periurbana en la Argentina. Escenarios, Recorridos y Problemas, Serie Monografías, $N^{0} 1$, Maestría de Estudios Sociales Agrarios, Buenos Aires: Facultad Latinoamericana de Ciencias Sociales (FLACSO), pp. 15-29.

CORBOZ, Andre. (2005): "El territorio como palimpsesto" en "Lo urbano en 20 autores contemporáneos". Ramos, A.M. (ed) Ediciones UPC. Barcelona.

INDOVINA, Francesco (2005) "La ciudad difusa" en "Lo urbano en 20 autores contemporáneos". Ramos, A.M. (ed) Ediciones UPC. Barcelona.

\section{Revistas}

BARSKY, Andrés (2005): "El periurbano productivo, un espacio en constante transformación". Introducción al estado del debate, con referencias al caso de Buenos Aires. Scripta Nova vol. IX, núm. 194. 
CUTINELLA, Adolfo. (1964), "Ingeniería sanitaria y planeamiento urbano", en Revista de la Facultad de Arquitectura, $N^{\circ} 5$. Montevideo, FADU - UDELAR.

DEMATTEIS, G. (1995) "Suburbanización y periurbanización. Ciudades anglosajonas y ciudades latinas" Urbanitats, 4.

GUIBERT, M.; GROSSO, S.; 2011; ARBELECHE, P.; BELLINI, M. "De Argentina a Uruguay: espacios y actores en una nueva lógica de producción agrícola" en Revista Pampa № 7, pp 13-38.

HERNÁNDEZ PUIG, Santiago. El periurbano, un espacio estratégico de oportunidad. Biblio 3W. Revista Bibliográfica de Geografía y Ciencias Sociales. [En línea]. Barcelona: Universidad de Barcelona, 25 de mayo de 2016, Vol. XXI, nº 1.160. . [ISSN 1138-9796].

PRADILLA COBOS, 2014 "La ciudad capitalista en el patrón neoliberal de acumulación en América Latina" en Cad. Metrop., São Paulo, v. 16, n. 31, pp. 37-60.

\section{Ordenanzas o decretos}

IDS- INTENDENCIA DEPARTAMENTAL DE SALTO (2016). Plan Local de Salto y su microrregión.

IDS- INTENDENCIA DEPARTAMENTA DE SALTO (1998). Plan de Salto.

IDF- INTENDENCIA DEPARTAMENTAL DE FLORIDA (2014). Plan Local de Florida y su microrregión.

REPÚBLICA ORIENTAL DEL URUGUAY. Leyes 10723 (de centros poblados), 10866 (ampliación de ley de centros poblados), 13728 (ley de vivienda), 18308 (de ordenamiento territorial y desarrollo sostenible).

\section{Fuentes electrónicas}

MARTÍNEZ, E,; ALTMANN, L., RODRIGUEZ, C (2013). "Incidencia de las ciudades intermedias en el sistema urbano nacional". Revista de la Facultad de Arquitectura. № 11. http://www.revista.edu.uy/11/2013/10/02/incidencia-de-las-ciudades-intermedias-ciu-en-la-conformacion-delsistema-urbano-nacional/ (consulta: 20/02/2018)

MARTÍNEZ, E. J (coord) (2007-2015) "Ciudades intermedias del Uruguay". Informes de investigación en www.fadu.edu.uy/itu/ciu . (consulta: 10/02/2018) 